\title{
China's water sustainability in the 21st century: a climate-informed water risk assessment covering multi-sector water demands
}

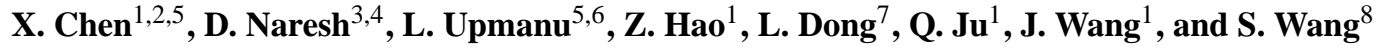 \\ ${ }^{1}$ State Key Laboratory of Hydrology-Water Resources and Hydraulic Engineering, Hohai University, Nanjing, 210098, China \\ ${ }^{2}$ Bureau of Hydrology, Changjiang Water Resources Commission, Wuhan, 430010, China \\ ${ }^{3}$ Department of Civil Engineering, The City University of New York (City College), New York, 10031, USA \\ ${ }^{4}$ NOAA-Cooperative Remote Sensing Science and Technology Center, The City University of New York (City College), \\ New York, 10031, USA \\ ${ }^{5}$ Department of Earth and Environmental Engineering, Columbia University, New York, NY 10027, USA \\ ${ }^{6}$ Columbia Water Center, The Earth Institute, Columbia University, New York, NY 10027, USA \\ ${ }^{7}$ Research Center for Sustainable Hydropower Development, IWHR, Beijing, 10038, China \\ ${ }^{8}$ Hydrology Bureau, Huai River Committee, Bengbu, 233001, China
}

Correspondence to: X. Chen (glbycx2012@gmail.com) and D. Naresh (ndevineni@ccny.cuny.edu)

Received: 12 August 2013 - Published in Hydrol. Earth Syst. Sci. Discuss.: 22 August 2013

Revised: 6 February 2014 - Accepted: 14 March 2014 - Published: 8 May 2014

\begin{abstract}
China is facing a water resources crisis with growing concerns as to the reliable supply of water for agricultural, industrial and domestic needs. High inter-annual rainfall variability and increasing consumptive use across the country exacerbates the situation further and is a constraint on future development. For water sustainability, it is necessary to examine the differences in water demand and supply and their spatio-temporal distribution in order to quantify the dimensions of the water risk. Here, a detailed quantitative assessment of water risk as measured by the spatial distribution of cumulated deficits for China is presented. Considering daily precipitation and temperature variability over fifty years and the current water demands, risk measures are developed to inform county level water deficits that account for both within-year and across-year variations in climate. We choose political rather than watershed boundaries since economic activity and water use are organized by county and the political process is best informed through that unit. As expected, the risk measures highlight North China Plain counties as highly water stressed. Regions with high water stress have high inter-annual variability in rainfall and now have depleted groundwater aquifers. The stress components due to agricultural, industrial and domestic water demands are
\end{abstract}

illustrated separately to assess the vulnerability of particular sectors within the country to provide a basis for targeted policy analysis for reducing water stress.

\section{Introduction}

Water stress in China is a widely recognized crisis. The simultaneous effects of agricultural growth, industrialization and urbanization coupled with declining surface and groundwater quantity, inefficiency in agricultural water use practices and cross-sectoral conflicts over limited water resources are some of the crucial problems (Cai, 2008). The effects of climate variability and change, including increasing frequency of extreme events such as droughts, creates additional pressure on the already scarce water supplies. Irrigated agriculture is the dominant water user in China, accounting for more than $60 \%$ of all consumptive use (http: //www.mwr.gov.cn/zwzc/hygb/szygb/). China has the highest net irrigated area $\left(6 \times 10^{7}\right.$ ha) in the world and the expansion of agriculture through improved irrigation infrastructure has been the key for increased food production for selfsustenance. In this context, ensuring sufficient water supply 
is a daunting challenge for sustainability in the 21st century. As competition for water increases across different use sectors and across different states, the temporal variability in available supply leads to increasing pressure to develop surface storage, or to use groundwater resources. Analyses that directly highlight the water stress faced locally relative to endogenous supply within a subregion can highlight the implicit degree of spatial competition for the resource and the impacts of temporal variability relative to an existing or projected demand scenario.

Water provision is usually a local issue, and decisions are often important at the county and province level. Other than large surface reservoirs and canal systems that ultimately serve a relatively limited area and concentrated population, most use and sources of supply are local or regional. Consequently, one needs analyses that directly highlight the water stress faced locally that relies on an endogenous supply which may have substantial temporal variability, and relative to an existing or projected demand scenario. Where local demands outstrip average annual local renewable supply, groundwater mining and/or transbasin diversions, which in turn are often supported by large surface storages, are relied upon. Hence, one needs to distinguish between two components of water stress. First, consistent with existing analyses, one needs to assess the relative difference between average demand and supply. Second, one needs to assess the implications of the temporal imbalance of supply and demand at a spatial resolution consistent with decision-making. The approach we present in this paper addresses both aspects integrally, considering endogenous water supply and demand for a geographical unit of interest.

Unlike past work that considers estimates of groundwater recharge and river flow as measures of supply (Oki and Kanae, 2006; Alcamo et al., 2003; Brown and Matlock, 2011 and references therein), we use local precipitation as the renewable water supply endogenous to the area, and consider natural and human uses of this water in order to highlight the degree to which a county is dependent on both endogenous and exogenous water supply for its needs. The renewable supply for each county is considered to be the direct precipitation on that county. This choice is motivated by the need to separate the spatial competition and use of the resource for an analysis of the purely locally induced stress, and to reveal settings where there is a high implicit dependence on external water sources, either through excessive groundwater use locally, or through the use of upstream river water that may subsequently be captured or depleted, as has happened in much of the Yellow River basin, and may be happening in other river basins. Within this framework, the impact of within- and multi-year droughts on available renewable water supply is explicitly assessed for each county.

With regard to temporal variations, we consider intraannual and inter-annual variations in precipitation input, and in the nature of demand. Demand variations in time are most pronounced for agricultural water use. Since this is a large use sector, and a significant portion of the water crisis in China is associated with the use of groundwater for irrigation, an explicit accounting of this sector is warranted. Agricultural productivity is closely tied to the ability to buffer variations in rainfall onset, the number of rainfall events, and the duration of dry spells in the wet season. Here, we apply two metrics presented in Devineni et al. (2013) to capture the influence of within-year dry periods (normalized deficit index - NDI) and of shortage across years (normalized deficit cumulated - NDC) as measures of water risk and map them for China at a county level. The computations are done using over 50 years of daily precipitation data and the current reported water use pattern for each county.

Section 2 presents the data sources and methodology. In Sect. 3 we summarize the water stress situation for China using the indices developed. Finally, in Sect. 4, some summary comments are offered.

\section{Data and methods}

Daily rainfall, maximum temperature, minimum temperature, mean temperature, wind speed, sunshine duration, relative humidity and pressure at 730 stations from 1951 to 2010 were obtained from the China Meteorological Data Sharing Service System (http://cdc.cma.gov.cn/home.do). Data with good quality at 588 stations from 1960 to 2009 (50 years) were spatially interpolated to each of the 2410 counties in mainland China. The renewable water supply was estimated as a fraction $(70 \%)$ of daily rainfall available over cropland and a smaller fraction $(30 \%)$ of rainfall available from the non-cropped area in the county. This conceptually resembles the process one can model for bare soil evaporation, soil moisture dynamics and runoff generation, and on average is consistent with estimates from physically based models for these processes as applied to China (Feng et al., 2007; $\mathrm{Wu}, 2007)$. For computing agricultural water demands, data on harvested crops (a total of 18 are selected for the study) and the total cropland for each county in 1990 were obtained from the EOS-Earth data library (http://eos-earthdata.sr.unh. edu/data/data1.jsp). Estimates on the county level crop sown area and net crop area of most recent year were obtained based on the above data set, data from the World Bank (http: //data.worldbank.org/indicator/AG.LND.ARBL.ZS) and recent cropping pattern changes (changes are small, the largest change is less than $10 \%$ at province level over the past 20 years) illustrated by Sun (2008). The planting season for each crop in each part of the country were taken according to the FAO and some local farmers. The daily crop water requirements for various crops were estimated based on FAO recommended crop coefficients and reference crop evapotranspiration using the Penman-Monteith equation (Allen et al., 1998). The crop water requirement modeled in this study assumes complete efficiency. However, since the actual water utilized in the farm is greater than the consumptive water 
use, one can parametrically adjust for the additional losses affected from the application efficiency. Industrial water demands are obtained from the 2011 China water resources bulletins (http://www.mwr.gov.cn/zwzc/hygb/szygb/) at the province level. Industrial water demand at city level from the latest province-specific water resources bulletins was used to proportionally disaggregate the province level data to county level data. Household water demand for each county was calculated using per-capita water consumption of $160 \mathrm{Lday}^{-1}$ and the 2011 population census (http://www.stats.gov.cn/ tjgb/rkpcgb/).

The water stress indices presented here were first developed and demonstrated in Devineni et al. (2013). They are based on the computation of the water storage capacity needed to meet the demand for a given sequence of supply (Lall and Miller, 1988; Thomas et al., 1963) accounting for temporal variation in supply and demand. The basic steps for the computation of these two indices are presented below. For the $j$ th geographical unit, the following quantities are defined:

$$
\begin{aligned}
& \text { deficit }_{j, t}=\max \left(\text { deficit }_{j, t-1}+D_{j, t}-S_{j, t}, 0\right) \\
& \text { deficit }_{j, t}=0, t=0 \\
& \text { SIC }_{j}=\max _{t}\left(\operatorname{deficit}_{j, t} ; t=1: n \cdot 365\right) \\
& \text { SII }_{j, y}=\max _{t}\left(\operatorname{deficit}_{j, t(y)} ; t=1: 365 ; y=1: n\right) ; \\
& \operatorname{deficit}_{j, t(y)}=0, t=0 ; y=1 \ldots n,
\end{aligned}
$$

where deficit ${ }_{j, t}$ refers to the accumulated daily deficit, $D_{j, t}$ to total water demand, $S_{j, t}$ to the total water supply volume, for geographical location $j$, and day $t$, and $y$ to a calendar or cropping year. The corresponding normalized indices are simply

$\mathrm{NDC}_{j}=\frac{\mathrm{SIC}_{j}}{\mathrm{AP}_{j}} ; \quad \mathrm{NDI}_{j y}=\frac{\mathrm{SII}_{j y}}{\mathrm{AP}_{j}}$,

where $\mathrm{AP}_{j}$ is the average annual rainfall volume (district area $\times$ average depth of precipitation) for district $j$.

The daily water deficit is defined as the difference between the daily water demand and the daily renewable water supply. The deficits are accumulated (Eq. 1) while setting negative accumulations to 0 . The maximum accumulated deficit in a given year divided by the average annual rainfall across the historical period is the NDI for that year. Similarly, the NDC is the maximum accumulated deficit for all 50 years divided by the average annual rainfall. The NDI is computed as one number for each year using historical daily rainfall data for the area and current daily water needs. It measures the maximum cumulated water shortage each year that needs to be provided for from ground or surface water storage or transfers from other areas. The deficit at the beginning of each year is set to 0 for the calculation of the NDI, but not for the NDC. The NDC is computed as one number over the historical climate record. It represents the largest cumulative deficit between renewable supply and water use over the entire period. Consequently, it reflects the stress associated with multi-year and within-year shortages at a location. With 50 years of data, the 5th largest NDI value indicates that there is an approximately $10 \%$ chance that water storage or transfers of that amount may be needed to meet demands at that location in any given year if multi-year droughts were not considered. A different way of looking at the same index is that it highlights the deficits associated with an annual probability of exceedance of $1 /(n+1)$ or $1 / 51$ for this application. The NDC indicates the worst case in 50 years. A detailed description of the mathematical model, along with applications and interpretation, can be found in Devineni et al. (2013).

\section{Results}

\subsection{Water supply and demand}

Rainfall over China has significant variation across regions and across years as shown in Fig. 1. The coastal regions and the southeast are well endowed with precipitation with low inter-annual variability, while the northwest and parts of north China have low average annual rainfall and high variations from year to year. Much of the country also experiences strong seasonality in rainfall. The monsoon occurs between June and September, and the rest of the year can be dry. Even within the monsoon season, there can be long periods of no rain, or monsoon breaks (Panchawagh and Vaidya, 2011; Yan and $\mathrm{Wu}, 2013)$, as well as periods of intense rainfall $\left(>10 \mathrm{~cm} \mathrm{day}^{-1}\right)$ even in otherwise arid regions. In a monsoonal climate, one needs to account for the cumulative water deficit for meeting water needs, at least at a daily time step (at which rainfall data and crop water requirements are available), consistent with the farmer's decision-making process to irrigate. The NDI and NDC presented here automatically account for the relative difference between average demand and supply over the accounting unit, and the temporal imbalance of supply and demand at a spatial resolution consistent with decision-making.

Figure 2 shows the current cropping pattern for 18 crops identified for this study as the net cropped area divided by the county area. The high-intensity cropping areas are mainly located in three regions: North China Plain (Huang River, Huai River, and Hai River), Northeastern plain (Songhua River, Liao River, and Heilongjiang River), and the Yangtze River plain in the middle and lower sections of the Yangtze River. It is notable that much of the dryland areas of the country that have intense agriculture also have a high inter-annual variability in rainfall manifest in the form of persistent droughts or floods. Irrigation from surface- or groundwater reserves is essential in this setting. The progression of intensive agriculture in these regions has led to groundwater depletion (Zheng et al., 2010). Figure 3 shows the water demand for the agricultural, industrial (including electric power), and domestic sectors, as well as the total demand across all the sectors. 

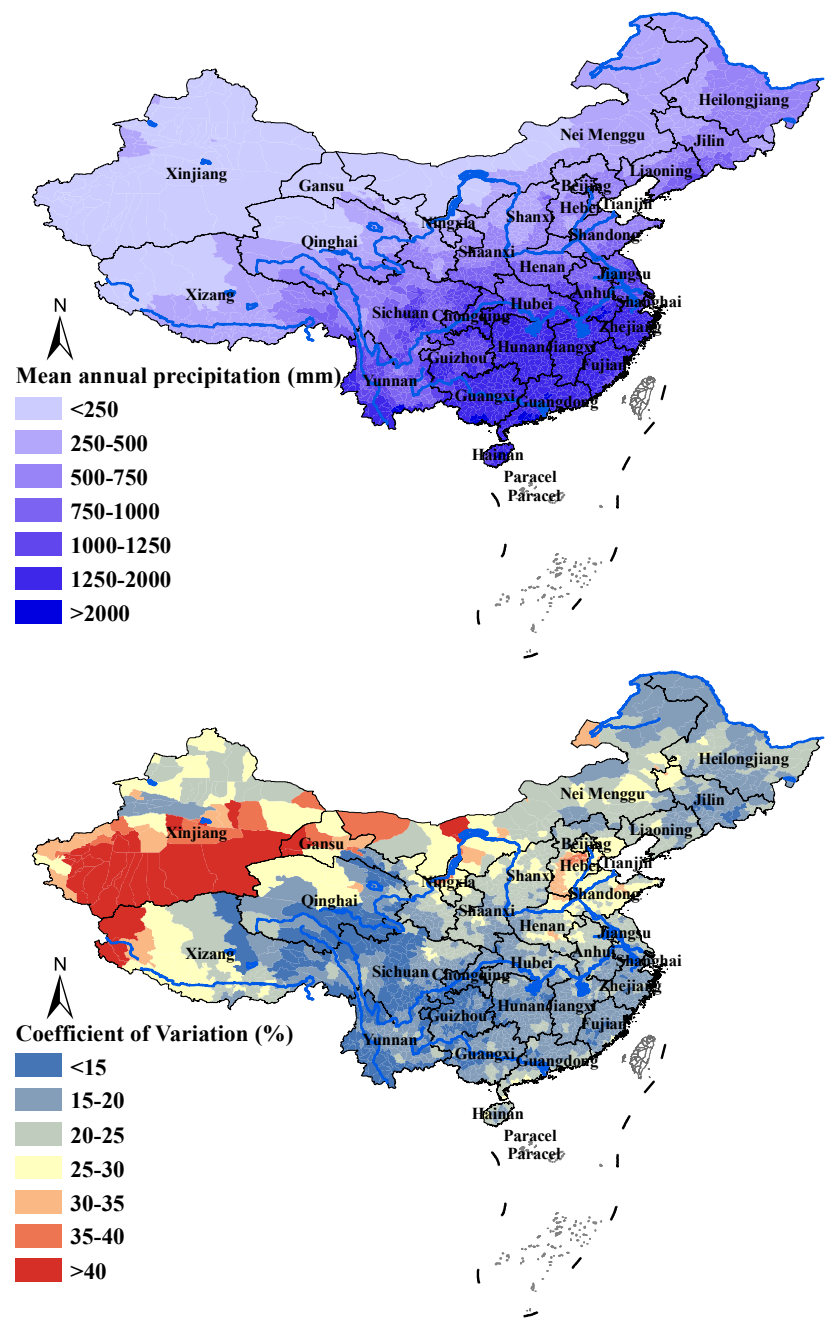

Fig. 1. Mean annual precipitation in $\mathrm{mm}_{\text {year }}{ }^{-1}$ and the associated coefficient of variation as $\%$ deviation from the mean.

The agricultural water demand is the sum of the water requirement as estimated from FAO-recommended crop coefficients and reference crop evapotranspiration for 18 crops in each county. High agricultural water demand emerges in South China and parts of Xinjiang. Rice, which is a waterintensive crop, is dominant in these regions. Similarly, human settlement and industrial productivity tend to happen in abundant water supply areas (South China and coastland region) or where additional water needs can be easily met from accessible surface water sources, (e.g., Yangtze River delta and Pearl River delta in this case).

\subsection{Intra-annual and multi-year water stress}

The intra-annual (NDI) and multi-year (NDC) water stress indices described above are computed for each of the 2243 counties (167 counties left black due to lack of sufficient matching data) in China using daily climate records from 1960 to 2009 and the most recent national statistics that

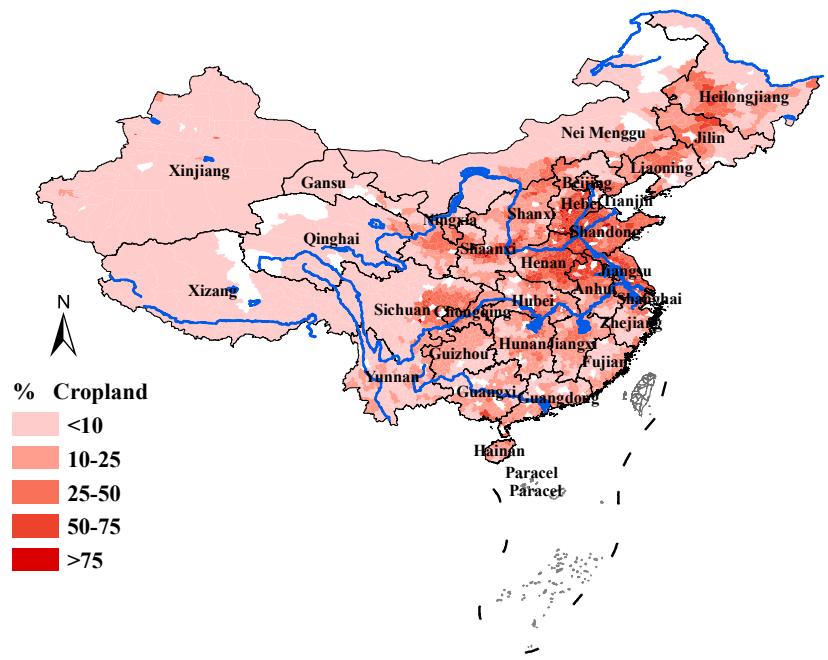

Fig. 2. Current China Cropping pattern as net cropped area/county area.

inform the current water use attributes for agriculture, industrial, and domestic water withdrawals. The maximum of the normalized deficit index (NDI.max, refers to the highest water stress in any year) and the normalized deficit cumulated (NDC, the maximum cumulated deficit over the whole period) are shown in Fig. 4a and b, respectively. NDI or NDC greater than 1 indicates that the magnitude of cumulative deficit is greater than the average annual rainfall in the local area. If the average NDI is greater than 1, then the annual rate of consumption in these regions is higher than the average utilizable rainfall rates.

From Fig. 4a we see that for the year with the worst deficit (this has a chance of happening once in 50 years), most of the country has $\mathrm{NDI}<1$, indicating moderate storage requirements or water stress. As one considers persistence beyond 1 year, we see from Fig. $4 \mathrm{~b}$ that the current use patterns portend severe stress over much of the North China Plain, middle and lower Yangtze River, as well as some most arid regions of Xinjiang. Consequently, across China, multi-year drought emerges as a more important concern than local imbalances in average supply and demand of water.

The worst situation is perhaps in Kashgar in Xinjiang province, located in the western Taklimakan desert, has the highest NDI.max (10.6) and NDC (534). This county requires more than 10 times the average annual rainfall almost every year in the past 50 years, since the annual rainfall here is only $60 \mathrm{~mm}$. Yarkant River is the main supplementary water source which maintains the development in this region. Another example is Jieshou County in Anhui province in the North China Plain, where water demand was always greater than renewable supply by 0.3 times the local average annual precipitation ( $820 \mathrm{~mm}$ or so) over the 50 years with NDI.max at 0.33 and $\mathrm{NDC}$ at 13.4 . 

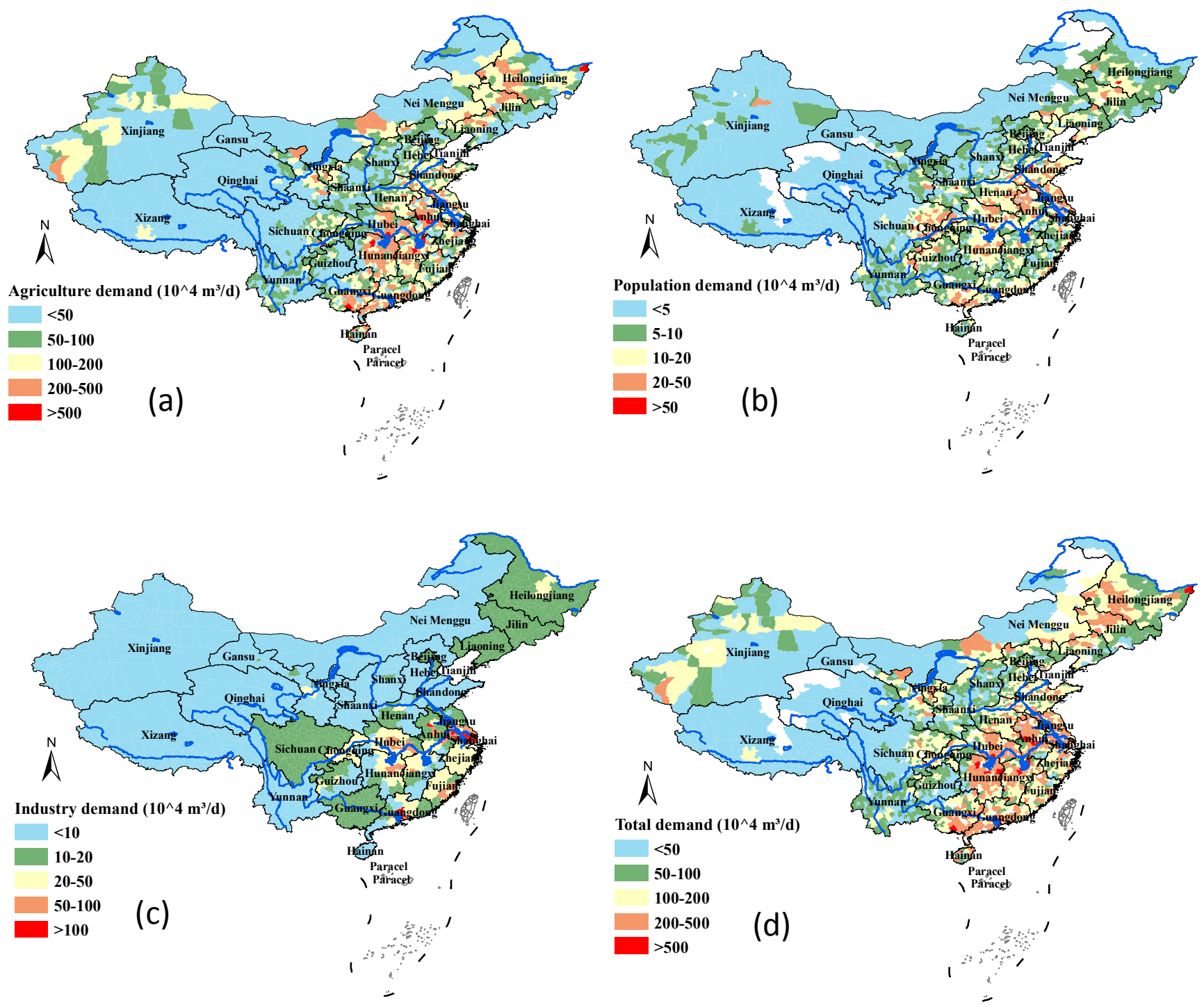

Fig. 3. Average daily water demand (agriculture, industry, household and total demand) for China in the most current year at county level.

Under these conditions, water storage structures and regional water transfers or groundwater pumping play a vital role in augmenting the surface water supply and groundwater recharge. Storage structures constitute one of the major interventions in the massive watershed development programs undertaken recently. Demand management and water use efficiency improvements are emerging as the target for addressing water security, as there is growing opposition to large infrastructure projects from social and economic perspectives, and due to the limited number of suitable sites for locating large storage and transfer schemes.

The sensitivity to different sources of water demand is shown in Fig. 4c and d. If we remove industry, it would have little impact on the total water stress over China apart from the Yangtze River delta and Pearl River delta (Fig. 4d). On the other hand, removing agriculture translates into water self-sufficiency across the country. Thus, despite the rapid increase in industrial water use in the recent period, it is food self-sufficiency that is the primary driver of water stress in China.

A question that arises is whether there is an opportunity to better allocate the resources across sectors while reducing the overall water stress. The extremely low cost of water encourages the production of crops that are both low-valued and highly water intensive and leads to a disincentive to use water efficiently. While changes in agricultural practices to more efficient techniques would reduce water stress, for a substantial reduction in water stress and effective water allocation across all sectors, one has to explore large-scale ideas such as spatial readjustment of crops coupled with dynamic agricultural market mechanisms that are informed by climate. The integration of more efficient irrigation technologies would 

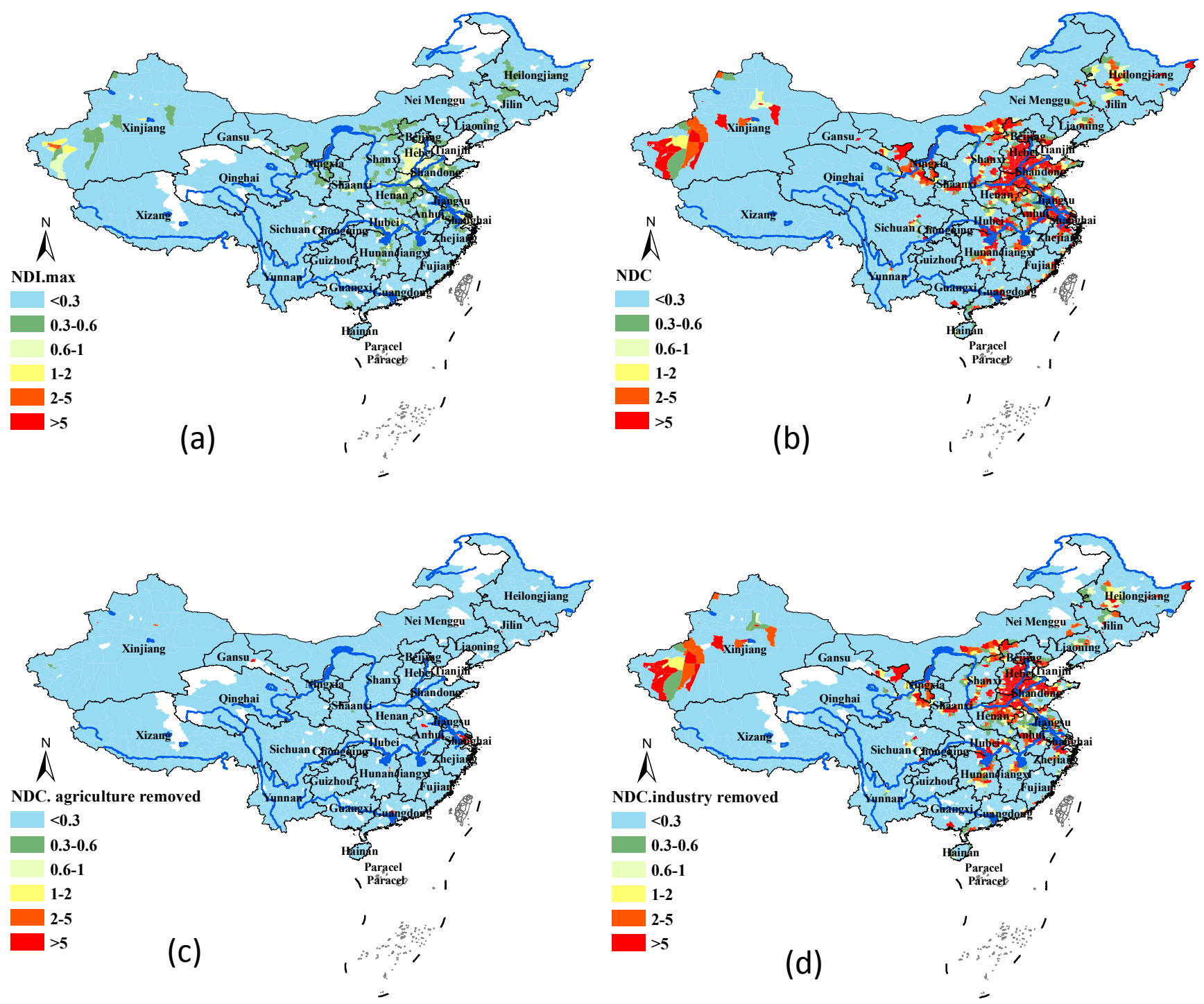

Fig. 4. Magnitude of water stress across China under within-year (NDI, a, and multi-year cumulative water stress analysis (NDC for total water demand, b; NDC.agriculture removed for water stress when agriculture water demand was removed, $\mathbf{c}$; NDC.industry removed for water stress when industry water demand was removed, d) for 1960-2009 daily supply and demand data (the magnitude 0.3 indicates that this county need 3 month rainfall volume to fill up the accumulative water deficits. Similarly, magnitude 5 indicates that this county needs 5-year rainfall volume to fill up the accumulative water deficits).

also be an important factor, and needs to be part of the economic model of demand transition. Of course, some reallocation across sectors, e.g. to energy and industrial use from agriculture, coupled with financial support to farmers for not irrigating during drought periods, and through better food storage and procurement would also significantly alleviate the problem.

\subsection{Spatial distribution of cross-year water stress and detection of monotonic trends}

A map that describes the regions susceptible to multi-year vs. within-year critical water shortage resulting from natural variations in climate relative to existing demand is provided in Fig. 5. The counties shown in blue have NDC equal the NDI.max, that is, multi-year shortages do not have an impact worse than that of the driest year on record. This could either be due to the absence of long droughts or due to a relative level of demand that is low enough to not require storage across years. Within the blue category, Shangcheng County in Henan province is the most stressed. The most severe water shortage in this region occurred in 2001 and is NDI. $\max =\mathrm{NDC}=0.24$ times the average annual precipitation. The counties marked in yellow have NDC greater than the NDI.max, and the ones marked in red have NDC $>10 \times$ NDI.max, indicating that multi-year deficit or 


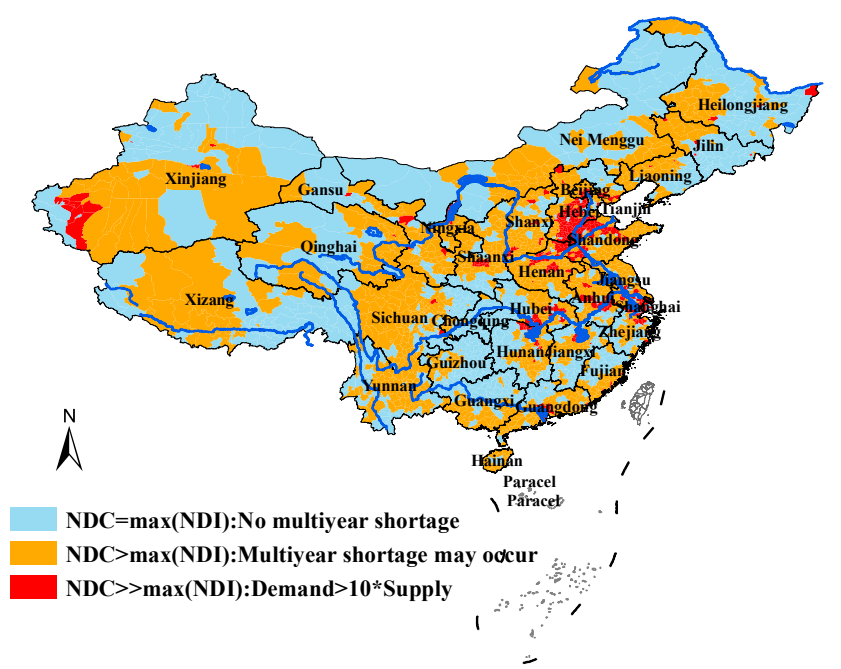

Fig. 5. Spatial categorization of the magnitude and distribution of water deficit risks in China. Blue: multi-year stress represents the worst single year stress. Yellow: multi-year stress is higher. Red: demand exceeds average annual endogenous supply in the county.

chronic impacts can be particularly severe. In these cases, demand reduction may be particularly beneficial unless a high amount of storage or diversion is available. Demands typically exceed total endogenous supply and reflect locations where groundwater mining or imported water is necessary to meet existing demands. These regions are in the North China Plain, middle and lower Yangtze River, Western Xinjiang province and the Pearl River delta, which have massive storage structures and excessive groundwater extractions.

Given concerns with trends due to anthropogenic climate change, we explored the monotonic trends in the NDI over the period 1960-2009 using the non-parametric MannKendall trend test (Mann, 1945; Helsel and Hirsch, 1992). The Mann-Kendall test is a rank-based test that is used for detecting trends in extremes with no assumption of the underlying distribution of the data. Figure 6 shows the results from the test for each county. The counties colored red indicate that the NDI has an increasing trend that is statistically significant at the $95 \%$ confidence level. Similarly, the counties colored green have a decreasing trend in NDI that is statistically significant at the $95 \%$ confidence level. The counties in white have no statistically significant trends. The large contiguous areas with decreasing trends in NDI, which reflect reduced persistence of dry days, are in western China and the Yangtze River basin. Wang et al. (2006) reported increasing rainfall trends in these regions. However, most parts of the North China Plain, the most severely stressed region, did not show signs of deficit reduction. In fact, some of the northeastern areas exhibit increasing trends in water stress due to climatic factors, contrary to the usual expectation that precipitation in high-latitude regions may increase under climate change. This may be in fact consistent with the

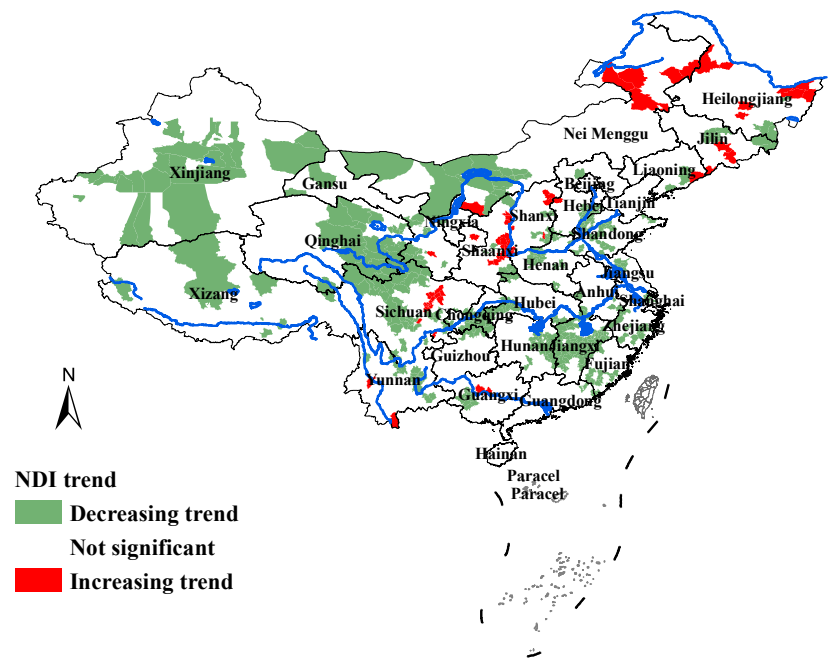

Fig. 6. Time trends in water stress (significance level $=95 \%$ ).

corresponding expectation that the intermittence of rainfall, i.e., the number of dry days, may actually increase, while the intensity of rainfall on wet days may increase. The NDI metric is sensitive to such changes at the daily level, while a metric based on average seasonal or annual rainfall would lead to the misleading conclusion that water conditions may improve in such regions under climate change.

In addition to the above analyses, we also compare our stress indices (NDI and NDC) to the average water stress measures (i.e., the ratio of average use to average supply) (e.g., Oki et al., 2001; Alcamo et al., 2003) in Fig. 7. The motivation here is to understand the relation between average stress and multi-year stress across the country, and also to explore the opportunity of deriving an empirical relationship that can provide reasonable approximations to climateinduced water stress (NDI or NDC) from simple estimates of average supply and average demand, thereby avoiding the need for detailed data on all the variables to compute NDC. This will be particularly useful for developing and understanding the real water stress globally using minimal data requirements. We can see that, in areas where the average value of NDI is greater than 0.1, the maximum NDI tends to be greater than 0.3 and NDC tends to be greater than 3 . In other words, if the magnitude of average stress is more than a tenth of mean annual rainfall volume, these counties typically experience a multi-year stress (as computed by NDC) and the cumulative deficit would exceed three times the mean annual rainfall. Similarly, in areas where average stress is greater than 0.3 , the maximum NDI tends to be greater than 0.7 and NDC tends to be greater than 15 , indicating huge stress. Thus, water stress across years has a non-linear relation with average stress. 

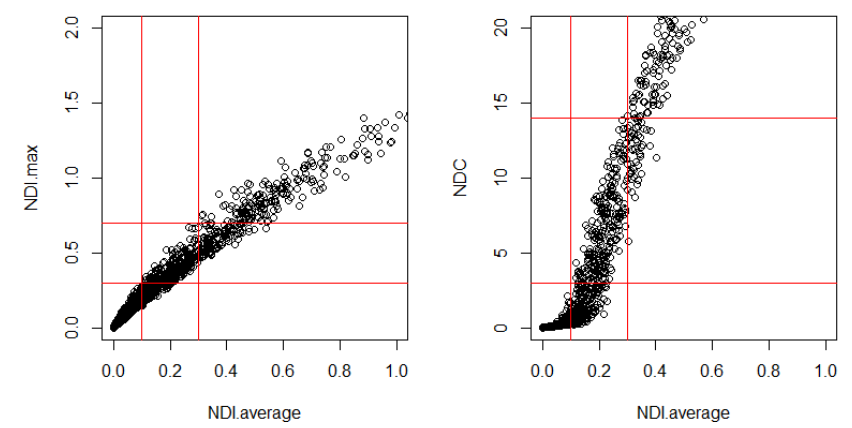

Fig. 7. The statistic relationship between average NDI, maximum NDI and NDC (the mark indicates how much water volume a county needs to fill up the accumulative water deficits; 0.3 indicates 3 months rainfall volume in that county; 5 indicates 5 years rainfall volume in that county).

\section{Discussion and summary}

Chronic water scarcity has emerged as a risk, as demonstrated in this paper for China (North China Plain) and in some of our previous work for northwest India (Devineni et al., 2013) and Midwest USA (Shi et al., 2013). Fossil aquifers, which have become the primary source of water supply, are being depleted at rates much faster than the natural recharge, which in turn is translating into an increasing marginal cost of supply. An attempt to develop a tractable modeling framework that conceptualizes the interaction between water supply and demand and quantifies the potential water stress at high spatial and temporal resolutions is made in this paper. We demonstrate that analyses at these timescales, recognizing the importance and sensitivity of the irrigation water requirements, reveal more accurate measures of water risk than those based on average supply and demand. Second, spatial units that reflect a user rather than supplier perspective may be more directly useful to decision-makers who must ultimately manage the resource within their political boundaries. This assertion forces one to change the analysis from the traditional watershed perspective to a county perspective. Integrated water management needs to consider watershed processes and boundaries. However, to be actionable, it also needs to recognize the constraints and the situation in political boundaries. Once one approaches the problem from this perspective, the spatial competition in the resource within a river basin and across river basins becomes important to map. Consequently, one needs to think in terms of the endogenous renewable supply within the political unit, and the implications for a current use structure if it has to rely on either fossil groundwater storage, or de facto transfers from exogenous sources through river or canal transport of water. These factors motivated the developments presented in this and related work.

It is well known that water requirements for industrial use and energy and mineral processing and production will continue to increase in China, as will the need for highquality domestic water use as living standards and economic factors continue to improve. An in-depth analysis and recommendations for water sustainability in China can be found in Cai and Lall (2012) and Cai (2008). Given the constrained water supply situation, addressing agricultural water use is clearly an important factor. Some possibilities in a broad global context are discussed in Lall (2013). Selected options are indicated here.

\subsection{Improvements in irrigation technology that improve water use efficiency}

There is substantial literature on the use of drip vs. sprinkler vs. flood irrigation, and application methods such as alternate furrow. Capital and labor cost factors, as well as the farm scale are typical limits to the adoption of these technologies. An alternative is to consider changes in watering practices, e.g., direct seeding of rice (Balasubramanium and Hill, 2002), system of rice intensification (Dobermann, 2004) and the use of soil moisture sensors (http://water.columbia.edu/home/research-themes/ water-food-energy-nexus/punjab-india/, Perveen et al., 2011).

\subsection{Macroscale policy for climate/water-informed crop diversification and public-private procurement systems}

Much of the current water stress in China, as in India, results from an intensification of agriculture facilitated by high water and fertilizer subsidies. In the process, the cropping patterns have departed significantly from traditional cropping patterns that were better attuned to the local climate. Consequently, developing market-based incentives and processes that facilitate investment in higher water efficiency through technologies and, more importantly, shifting crop production to regions better suited from a climate/water perspective for a particular crop, emerge as key solutions to the current and emerging stress. Formal analyses in this direction need to be pursued.

\subsection{Water transfer or food transfer}

The impact of the south to north water transfer project on the space and time distribution of water stress was not analyzed here. However, a formal consideration of such largescale transfers in the context of the formulation of a policy for institutionalizing water reallocation would better inform the water crisis and its solution. It is well known (Brown and Lall, 2006) that reducing water supply variability through storage can enhance water security, agricultural productivity and economy. For Jieshou County (in Fig. 8) the 50th and 90th percentiles of the NDI are identified as the reference for water storage required to meet the needs at the 50 and $90 \%$ reliability levels, respectively. The probability distribution of 


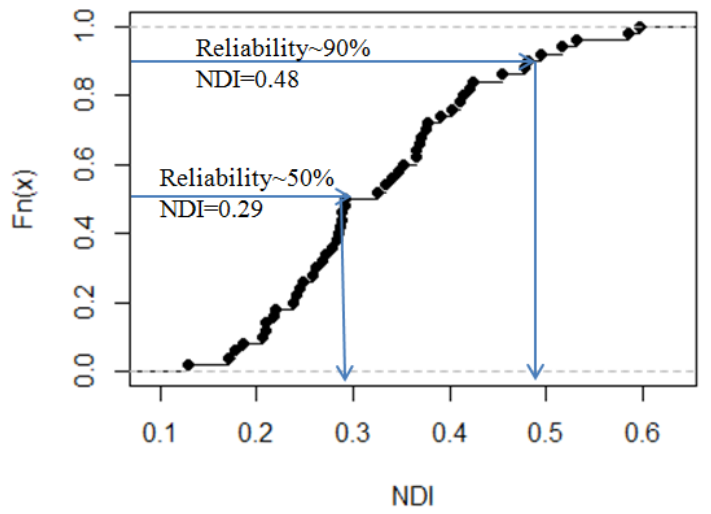

Fig. 8. Cumulative distribution function using the 50 years of NDI for Jieshou County (NDC is 13.4 , located in Anhui province). The 50th and 90th percentiles are highlighted.

stress (storage needed) would also allow consideration of formal risk management strategies or risk exposure analysis relative to existing utilizable storage in an area, offering a new financial risk management option. Since there is much interest in scenarios for future sustainability, one would need plausible daily climate realizations for the future, in conjunction with scenarios for water use. Each of these is feasible to develop under appropriate assumptions, and could be pursued to develop IPCC-style scenarios for supply and demand (e.g., assuming conservation programs, or changes in spatial crop allocation), and one could report the storage needed, assuming different levels of reliability. Likewise, trade-offs between food and water storage strategies could be examined in a probabilistic framework. This would be very useful as indicators of each region to provide a scientific basis for the water resources' allocation. As mentioned in Sect. 4, one could also pursue technological solutions at the local scale, market solutions at regional to global scale, and policy solutions (such as crop allocation optimization) at a national scale considering food and water storage as decision variables targeting desired reliability levels and contingency strategies to cover potential failures in food security. Similarly, micro-modification in the distribution of industry can also be done to relieve water stress according to industrial water consuming patterns.

Acknowledgements. The authors would like to thank the editor and two anonymous referees who kindly reviewed the earlier version of this manuscript and provided valuable suggestions and comments. We also thank China Meteorological Data Sharing Service System and EOS-Earth data library for providing the data used in this study. The work was funded in part by the Columbia Water Center, the Pepsico Foundation, China Scholarship Council, the National Basic Research Program of China (Grant No. 2010CB951103), National Natural Science Foundation of China (41271042, 41101015, and 41101016), Liaoning Social Science Foundation of China (L12BZZ010), Nonprofit Industry Research Special Fund of MWR (201101003) and the Special
Fund of State Key Laboratory of Hydrology-Water Resources and Hydraulic Engineering (1069-50985512).

Edited by: R. Merz

\section{References}

Alcamo, J., DÖLL, P., Henrichs, T., Kaspar, F., Lehner, B., Rösch, T., and Siebert, S.: Global estimates of water withdrawals and availability under current and future "business-as-usual" conditions, Hydrolog. Sci. J., 48, 339-348, 2003.

Allen, R. G., Pereira, L. S., Raes, D., and Smith, M.: Crop evapotranspiration - Guidelines for computing crop water requirements, FAO Irrigation and drainage paper 56, FAO, Rome, 300, 6541-6556, 1998.

Balasubramanian, V. and Hill, J. E.: Direct seeding of rice in Asia: emerging issues and strategic research needs for the 21st century, Direct-seeding: Research strategies and opportunities, IRRI, Los Baños, Philippines, 15-39, 2002.

Brown, C. and Lall, U.: Water and Economic Development: The Role of Variability and a Framework for Resilience, Nat. Resour. Forum, 30, 306-317, doi:10.1111/j.1477-8947.2006.00118.x, 2006.

Brown, A. and Matlock, M. D.: A review of water scarcity indices and methodologies, White Paper, The Sustainability Consortium, University of Arkansas, Arkansas, USA, 106, 19-37, 2011.

Cai, X.: Water stress, water transfer and social equity in Northern China - Implications for policy reforms, J. Environ. Manage., 87, 14-25, 2008.

Devineni, N., Perveen, S., and Lall, U.: Assessing chronic and climate induced water risk through spatially distributed cumulative deficit measures: A new picture of water sustainability in India, Water Resour. Res., 49, 2135-2145, doi:10.1002/wrcr.20184, 2013.

Dobermann, A.: A critical assessment of the system of rice intensification (SRI), Agricult. Syst., 79.3, 261-281, 2004.

Feng, H., Zhao, X. N., and Wu, P. T.: Analysis on influencing factors and improving approaches of crop utilization efficiency for rainfall in farmland at the Loess Plateau, J. Agr. Sci. Technol., 9, 30-35, 2007.

Helsel, D. R. and Hirsch, R. M.: Statistical methods in water resources, Stud. Environ. Sci., 49, 522 pp., 1992.

Lall, U. and Miller, C. W.: An optimization model for screening multipurpose reservoir systems, Water Resour. Res., 24, 953968, 1988.

Lall, U.: Global freshwater and food security in the face of potential adversity, in: Food Security and Sociopolitical Stability, edited by: Barrett, C. B., Oxford University Press, 2013.

Mann, H. B.: Nonparametric tests against trend, Econometrica, J. Econ. Soc., 13, 245-259, 1945.

Oki, T. and Kanae, S.: Global hydrological cycles and world water resources, Science, 313, 1068-1072, 2006.

Oki, T., Agata, Y., Kanae, S., Saruhashi, T., Yang, D., and Musiake, K.: Global assessment of current water resources using total runoff integrating pathways, Hydrolog. Sci. J., 46, 983-995, 2001.

Panchawagh, N. V. and Vaidya, S. S.: Link between break/active phases of summer monsoon over India and China, Current Sci., $100,1-8,2011$. 
Perveen, S., Krishnamurthy, C. K., Sidhu, R. S., Vatta, K., Modi, V., Fishman, R., Polycarpou, L., and Lall, U.: Restoring groundwater in Punjab, India's breadbasket: Finding agricultural solutions for water sustainability, Columbia Water Center White Paper, Columbia Water Center, Earth Institute, Columbia University, New York, NY, 2011.

Shi D., Devineni, N., Lall, U., and Piñero, E.: America's Water Risk: Water Stress and Climate Variability, Columbia Water Center White Paper, Columbia Water Center, Columbia, 2013.

Sun, F.: Study on adaptive capacity of agriculture to climate changecropping pattern and technologies perspective, $\mathrm{Ph} . \mathrm{D}$ thesis, Chinese Academy of Agricultural Sciences, Beijing, China, 2008.

Thomas, J. R., Harold, A., and Robert, P. B.: Operations Research in Water Quality Management, Water Resources Group, Harvard Univ. Cambridge Mass. Div. of engineering and applied physics, Cambridge, Mass., 1-17, 1963.
Wang, Y., Cao, M. K., Tao, B., and Li, K. R.: The characteristics of spatio-temporal patterns in precipitation in China under the background of global climate change, Geogr. Res., 25, 1031-1041, 2006.

$\mathrm{Wu}, \mathrm{P}$. T.: Rainwater harvesting and modern water saving agriculture, J. Agr. Sci. Technol., 9, 15-20, 2007.

Yan, D. H., Wu, D., Huang, R., Wang, L. N., and Yang, G. Y.: Drought evolution characteristics and precipitation intensity changes during alternating dry-wet changes in the HuangHuai-Hai River basin, Hydrol. Earth Syst. Sci., 17, 2859-2871, doi:10.5194/hess-17-2859-2013, 2013.

Zheng, C., Liu, J., Cao, G., Kendy, E., Wang, H., and Jia, Y.: Can China Cope with Its Water Crisis? - Perspectives from the North China Plain, Ground Water, 48, 350-354, doi:10.1111/j.17456584.2010.00695_3.x, 2010. 